\title{
National Cultural Constructs and Consumer Socialization Effects on Adolescent's Influence on Family Vacation Decisions
}

\author{
By João Paulo Baía*
}

\begin{abstract}
With the expansion of globalization, the search for new markets and the interest of companies in the knowledge of how, in specific cultures, families structure their purchase decisions, is of particular relevance nowadays. Literature has evidenced the existence of diverse cultural dimensions, namely individualism-collectivism and power distance. In addition, the family buying decisions is one of the most difficult consumer behavior subjects. Thus, adolescents became an increasingly attractive segment for companies, because they are considered as an active element and have influence the most important consumption unit, the family. However, services for family use have not yet been properly studied. This research main goal is to examine the influences of the national cultural constructs of individualism-collectivism and power distance, and consumer socialization effects on adolescent's influence on family vacation decisions. A quantitative research method is utilized in high schools in Lisbon district, Portugal. 1,800 questionnaires were delivered in classrooms during May 2018. Adolescents were instructed to deliver questionnaires to their mothers, and 726 validated questionnaires were returned. Results of logistic regression analysis point to individualism, parental communication style, internet influence, television influence, adolescent's service knowledge, family size and structure as purchase important explanatory variables. Several contributions are made to this knowledge area. Firstly, the importance of including the adolescent in purchases for family use is reinforced. Secondly, marketers should focus their efforts on adolescents more individualistic, with more permissive parenting styles families, more influenced by internet and television, with greater service knowledge, and from single-parent and larger families. These results are innovative. A contribution to companies is offered by providing evidence of adolescent's influence on family purchases. Given their importance on family decisions, it is important that marketers focus their efforts on adolescent satisfaction.
\end{abstract}

Keywords: Consumer Behaviour, National Cultural Constructs, Consumer Socialization, Family Decision Making, Adolescent, Influence, Family Vacations.

\section{Introduction}

Literature has evidenced the existence of significant cultural differences between countries, and these differences manifest themselves in the various cultural dimensions, namely individualism-collectivism and power distance (Al-Zu'bi 2016, Yang et al. 2014, Feng et al. 2011). For marketers, the search for new markets is very important in the context of globalization, and being the most important decision-making and consumption unit, it's most relevant the understanding of how families in different cultures make consumption decisions (Ishaque and Tufail 2014, Kaur and Medury 2013, Leng and Botelho

*Adjunct Professor, Polytechnic Institute of Setubal, Portugal. 
2010). In addition, the family buying decision process is considered one of the least researched and difficult subjects within consumer behavior (Aleti et al. 2015, Akinyele 2010, Beatty and Talpade 1994, Belch et al. 1985). In that context, adolescents constitute an important segment for companies, mainly for the influence they exert on family purchase process (Al-Zu'bi 2016, Mau et al. 2016, Kaur and Medury 2013, Luczak and Younkin 2012). Thus, it is important for marketers to understand adolescent consumer patterns (Luczak and Younkin 2012).

One main service for families' use in which joint decisions tend to occur is vacations (Watne and Winchester 2011). The way that families with adolescents make joint vacation decisions can be much more complex than past research has pointed out (Watne et al. 2014). Several researchers pointed the importance to study culture concept for use in international marketing to review proper applications of cultural constructs (Mooij 2015, Feng et al. 2011). For Aleti et al. (2015), "understanding how socialization agents transfer knowledge to learners is important to marketers because it offers the opportunity to stimulate consumer knowledge and, consequently, purchases within joint decisionmaking units such as the family" (Aleti et al. 2015: 173).

Consumer socialization is the processes through which consumption related skills, knowledge, and attitudes are transferred between generations (Aleti et al. 2015, Yang et al. 2014, Watne et al. 2011, 2014, Ward 1974). Adolescent's socialization has been successful predicted by parental communication. Nevertheless, the effect of parental communication style in adolescents' perceived influence on buying decisions is still unexplored (Sharma and Sonwaney 2013).

In recent times, consumer socialization theorists have explored the effect of socialization agents on adolescents, including television (Kushwaha 2017, Moschis and Moore 1979). However, there's also a lack of research testing the impact of internet on adolescents' consumer socialization (Sharma and Sonwaney 2013, Niu 2013, Luczak and Younkin 2012).

Previous research on family vacation has been limited because there is little consideration of the impact that adolescents can have on decision-making process (Watne et al. 2014). The dominant social group on which people spend their vacation is the family, and also the most important social structure for companies that supply that service (Baía 2018, Khoo-Lattimore et al. 2016, Carr 2006). In this context, it is fundamental for marketers to study the family in its various forms (Kaur and Medury 2013, Shoham and Dalakas 2005, Lee and Beatty 2002, Commuri and Gentry 2000). Given the limited research on the adolescent's influence on family buying decisions, several authors refer to the need to deepen the study of this phenomenon (Kaur and Singh 2006, Commuri and Gentry 2000). Adolescents have increasingly become the focus of both research and companies (Ashraf and Khan, 2016, Mau et al. 2016, 2014, Goswami and Khan 2015, Srivastava 2015). The efforts made by adolescents in family purchases have increased nowadays (Sondhi and Basu 2014, Singh and Nayak 2014, Chitakunye 2012, Kaur and Medury 2011).

The substantial and growing adolescent market needs marketers to understand the adolescent purchase behavior for current sales and their participation in the 
family structure (Niemczyk 2015, Srivastava 2015, Shahrokh and Khosravi 2014, Yang et al. 2014). There is a good stream of research which has shown that adolescents' role in family purchase decisions varying by product, decision stage, adolescent, parental, and family characteristics (Aleti et al. 2015, Ishaque and Tufail 2014, Shahrokh and Khosravi 2014, Shergill et al. 2013, Ali et al. 2013, Chaudhary and Gupta 2012).

This study examines the influence of the national cultural individualismcollectivism and power distance constructs, and consumer socialization effects on adolescent's influence on family vacations purchase decision, whose interest derives from the literature (Khoo-Lattimore et al. 2016, Aleti et al. 2015, Kim et al. 2015, Feng et al. 2011, Watne and Winchester 2011, Kaur and Singh 2006). The present research presents a holistic approach to the topic of adolescent influence, also considering the influence of service knowledge on his/her participation, and the influence of demographic variables such as household size and family type (Baía 2018, Ali et al. 2015). This paper also explores the role of television and internet as antecedents to consumer socialization of adolescents and its effects on their purchase influence.

Although past literature indicates the adolescent as an influential element of family vacations purchases (Khoo-Lattimore et al. 2016, Niemczyk 2015, Kaur and Medury 2011, Mangleburg 1990, Foxman et al. 1989a, b), a holistic approach to the adolescents' influence on parent's vacations final decision remain unresearched (Baía 2018, Khoo-Lattimore et al. 2016, Niemczyk 2015, Kaur and Medury 2011, Akinyele 2010, Kaur and Singh 2006). The subject of the present investigation is the consumption behavior of family vacations purchase.

There is a main theoretical dimension in the research problem which essentially involves the answer to the following questions: What is the impact of the national cultural constructs and consumer socialization on adolescent's influence on family vacation decisions? What are the family demographic characteristics that impact the adolescent's influence on family vacations purchase decisions? What is the mother's perception about the adolescent's influence?

The paper begins with the literature review and the research hypotheses definition. Then the methodology used will be characterized. The main research results will be presented and they will be discussed, as well as the main conclusions, limitations and directions for future research.

\section{Literature Review and Hypotheses}

The family consumption behavior domain presents some gaps, among which, the adolescent's influence is often underestimated or omitted, with regard to purchasing decisions (Khoo-Lattimore et al. 2016, Watne and Winchester 2011, Kaur and Medury 2011, Carr 2006). Past research on traditional families found out that the adolescent is considered as a less relevant member when considering family purchasing decisions. 


\section{The Adolescent Role}

Past research has identified adolescents as relevant direct or indirect influencers of the purchase of a large amount of household items, and a very important future market of a larger variety of products and services (Aleti et al. 2015, Srivastava 2015, Shahrokh and Khosravi 2014). The adolescent is an influencing member on family purchasing decisions within consumption unit, and this influence is manifested directly, that is, by actively acting in the direction of a certain decision (Kaur and Singh 2006, Beatty and Talpade 1994, Mangleburg 1990). For several researchers, the adolescent's influence on family buying decisions is not adequately explained (Aleti et al. 2015, Shergill et al. 2013, Chaudhary and Gupta 2012, Kaur and Singh 2006).

On family vacation decisions there has been argued that adolescent participation is minor or null in the final stage (Khoo-Lattimore et al. 2016, Watne and Winchester 2011, Kaur and Medury 2011, Carr 2006). Niemczyk (2015) in his study on holidays decisions, concluded that adolescents have some say in the final decision solely in the case of domestic holidays, but they do not participate in that phase when it is concerned holidays more planned and abroad. Ashraf and Khan (2016) found an adolescent "decline in the involvement may be because family vacation is a high-budget decision and parents might be more involved in the final decision-making stage" (Ashraf and Khan 2016: 396). However, Baía (2018) found adolescents actually revealed an active participation on that service decision. Those contradictious results emphasize the existence of a gap regarding the study of the adolescent's participation in the decision phase of family vacations purchases. Thus, the study of that purchase lacks deeper connection and there's some evidence that one can expect that the effect of other variables should be studied, like national cultural constructs, consumer socialization, and some demographic family characteristics to have important effects on adolescent's influence on family vacation decisions.

\section{National Cultural Constructs}

In research of national values of different societies, Hofstede (1994: 4) defines culture as the "collective programming of the mind which distinguishes the members of one group or category of people from those of another". Hofstede (2001) has identified several dimensions of national culture including individualism vs collectivism and power distance, to determine the impact of culture constructs on individual consumer behaviour (Al-Zu'bi 2016). Individualism versus collectivism refers to the country's cultural position in relation to the individual or group importance, that is, to what extent is the individual or society more valued (Chan and McNeal 2003, Hofstede 1993).

\section{Individualism vs Collectivism}

Individualism versus collectivism refers to a country's cultural position relative to the individual or group's importance (Chan and McNeal, 2002a, 
Hofstede 1994, 1993). The distance to power is related to the desire in a society by hierarchy versus egalitarianism (Chan and McNeal 2002a). The individuals from collectivist culture devote more attention to their families and sacrifice themselves for the communal interests of the affiliated groups than the individualistic people (Al-Zu'bi 2016). People from individualist cultures use the term "I" in their speech, while the people of the collectivist cultures frequently use the term "We" in their arguments (Mooij and Hofstede 2010). For Yang and Laroche (2011), "in Western cultures, the development of self is more separate, distinct, and independent of others. Therefore, acceptance and support from parents are sufficient for adolescents to establish a strong positive attitude toward themselves" (Yang and Laroche 2011: 9). Thus, the first hypothesis is:

H1: The adolescents will be perceived as having more influence on family purchases if they are in individualist culture than if they are in collectivist culture.

\section{Power Distance}

Hofstede (1993) has defined power distance as "the degree of inequality among people which the population of a country considers as normal: from relatively equal (that is small power distance) to extremely unequal (large power distance)" (Hofstede 1993: 89). Thus, power distance is related with the desire for a more hierarchical society or, in opposition, with the wish for a more egalitarian society (Chan and McNeal 2003). The power distance is reflected in the fact that, in a society, members who hold less power accept that power is distributed with iniquity (Hofstede 1993). Based on Hofstede (1993), it can be concluded that Western Europe countries have a low power distance. This means that parents in those countries value the obedience of adolescents compared to parents in cultures with a higher power distance. Therefore, those parents are more likely to encourage and be more open to the participation of adolescents on family decisions (Shergill et al. 2013). So, the second hypothesis is:

H2: The adolescents will be perceived as having more influence on family purchases if they are in low power distance culture than in high power distance culture.

\section{Consumer Socialization}

Adolescents' influence on consumption decisions of their parents largely depends on socialization factors such as the parental communication style, internet influence, and television influence (Aleti et al. 2015, Watne et al., 2011, 2015, Haq and Rahman 2015, Barber 2013, Kaur and Medury 2011). Amongst the diverse agents identified, parents, peers and media have received the most attention (Aleti et al. 2015, Dotson and Hyatt, 2005, Moschis and Churchill 1979). 


\section{Parental Communication Style}

Parental communication style and effect on adolescent's socialization process depends, in great extent, on the parental orientation, being more restrictive or more permissive (Kushwaha 2017, Al-Zu'bi 2016, Kim et al. 2015, Yang and Laroche 2011). Several authors pointed, on the basis of concept-oriented style (COS) and socio-oriented style (SOS), four types of parental communication patterns were identified: (i) Laissez-faire (low COS, low SOS); (ii) Protective (low COS, high SOS); (iii) Pluralistic (high COS, low SOS); and (iv) Consensual (high COS, high SOS) (Sharma and Sonwaney 2013, Rose et al. 1998, Moschis and Moore 1979). The laissez-faire family is believed to have weak correspondence between parent and adolescent, the protective family demonstrates social amicability where adolescent could gain knowledge all alone to a limited extent; the pluralistic family fosters the adolescent to practice open communication, while the consensual family allows the adolescent to develop his or her own perspective on family cohesiveness (Carlson and Grossbart 1990). Past research pointed that parents with concept-oriented style consult adolescents and value their opinions in purchase decisions (Sharma and Sonwaney 2013, Rose et al. 1998, Moschis and Moore 1979).

According to Watabe and Hibbard (2014), parents with socio-oriented communication style seek to promote obedience by monitoring and controlling adolescents' consumer learning and behavior. Those researchers found that in permissive parenting style, adolescents testify that "mother did not view herself as responsible for directing and guiding my behavior as I was growing up" (Watabe and Hibbard 2014: 364).

As Rose et al. (1998) pointed, "Consensual and pluralistic mothers held more negative attitudes toward advertising than laissez-faire mothers" (Rose et al. 1998: 80). Therefore, the third hypothesis is:

H3: Adolescents with laissez-faire and pluralistic parents will be perceived as having more influence on family purchases than those with protective and consensual parents.

\section{Internet Influence}

For Kaur and Medury (2011), worldwide there has been a huge explosion in internet use, and has been a major influence on the way adolescents socialize. According to Luczak and Younkin (2012), considering the internet use as a vehicle and through its contents, it should influence adolescents' knowledge through direct experience. More, the "internet use as a vehicle and through its content, aides the formation of adolescents' attitudes towards consumption through the development of their consumption knowledge and skills" (Luczak and Younkin 2012: 49). Further, adolescents are also known to be more skilled in engaging with internet than parents. For these reasons, adolescents' internet use is also a matter of interest to academicians and marketeers (Kaur and Medury 2011, Belch et al. 2005). Thus, the perception of the effects of the 
socialization of adolescent consumption by agents such as the internet and television are an area of great interest in our days. The increasing use of the internet as a communication tool makes this a potentially strong socialization agent (Lee et al. 2003).

Adolescents experience the internet as a physical and social space, allowing people to talk, form relationships, discuss issues and perform many of the social tasks normally performed in the physical environment (Kaur and Medury 2011).

For Barber (2013), the internet should be considered as a potential socializing agent with a significant impact on adolescents. According to Kaur and Medury (2011), the influence of internet on the adolescent would significantly relate to his/her role in decision making. Thereby, it is expected that:

H4: Internet influence will be positively related to the adolescent's influence on family purchase decisions.

\section{Television Influence}

Informative influences of traditional mass media help guide consumers to products and brands through providing credible evidence (Barber 2013), often using the persuasive power of reputable informants such as media sources. The most influential of the mass media has been the television through advertising what brands are acceptable by society or supported by celebrities (Churchill and Moschis 1979, Moschis and Mitchell 1986). Television's influence is mostly expressive, affecting attitudes such as desire for products, brand preference, and a sense of belonging (Barber 2013). For Haq and Rahman (2015), television helps adolescents to develop product-related knowledge, consumer-role perception and influences their purchasing intentions.

Mangleburg and Bristol (1998) found that the degree of television viewing improves the adolescent's marketplace knowledge. Kushwaha (2017) found that parents who regularly watch television with adolescents could control the content to be watched and thus feel need of less intervention.

For Sharma and Sonwaney (2013), "children who received more parental restriction regarding television viewing tended to be less conscious of brand names" (Sharma and Sonwaney 2013: 34). So, one can expect that:

H5: Television influence will be positively related to the adolescent's influence on family purchase decisions.

\section{Service Knowledge}

Social power relates to a person's ability to persuade or influence others based on some attribute such as knowledge or expertise (Aleti et al. 2015, Beatty and Talpade 1994). In the case of adolescents influencing their parents in purchase decisions, such power comes from expertise and knowledge about a certain product or service (Watne et al. 2011, Beatty and Talpade 1994). Chitakunye 
(2012) pointed that adolescents are motivated by parents to use their cognitive skills in consumer decisions. Adolescents tend to be most knowledgeable and interested in leisure travelling, which lead to more influence attempts (Aleti et al. 2015, Watne and Winchester 2011). Baía (2018) found that adolescents actually revealed an active participation on vacation decisions when their service knowledge is high.

Thus, the service knowledge should lead to greater adolescents' influence attempts and more parental receptiveness (Chitakunye 2012, Belch et al. 2005, Shah and Mittal 1997, Beatty and Talpade 1994). Thus, the sixth hypothesis is:

H6: The adolescents will be perceived as having more influence on family purchases if they have greater service knowledge than if they have minor knowledge.

The family type is considered as an important factor when explaining the influence of the adolescent in the decisions of purchase in the family, with the adolescents in single-parent families to present significantly higher levels of influence comparatively to those from traditional families (Mangleburg et al. 1999, Ahuja et al. 1998, Ahuja 1993, Ahuja and Walker 1994, Ekstrom et al. 1987, Darley and Lim 1986). For Lackman and Lanasa (1993), the change in the influence of adolescents seems to emerge from a number of factors, the increasing increase in divorce rates (Caruana and Vassallo, 2003, Ekstrom et al. 1987). Ahuja (1993), in a comparative study between single-parent and traditional families, concluded that in their role as junior partners in the performance of management activities and emotional support of the mother, adolescents in single-parent households could also participate in decisionmaking process at a higher level than adolescents in traditional families. Ahuja and Walker (1994) found that children in single-parent families seem to have more influence on the purchasing decision process than their peers in traditional families (Caruana and Vassallo, 2003, Mangleburg et al. 1999, Ahuja 1993, Darley and Lim 1986, Ekstrom et al. 1987). For Ashraf and Khan (2016), Lackman and Lanasa (1993) and Ekstrom et al. (1987), the rise in single-parent families have led to an increase in the say adolescents have in family purchase decisions. Thus:

H7: The adolescents will be perceived as having more influence on family purchases if they live in single-parent families than if they live in traditional families.

Predominantly, past research has included the family characteristics as explanatory of the adolescent's influence on family purchase decisions (Kushwaha 2017, Watne et al. 2014, Neulinger and Zsoter 2014, Kaur and Medury 2013, Shergill et al. 2013). The family size was more frequent and recently considered a variable in the study of family buying decisions, with the authors pointing that the adolescent will have greater influence on purchases on larger families (Ahuja 1993, Ahuja and Stinson 1993). Therefore, it is expected that: 
H8: The adolescents will be perceived as having more influence on family purchases if they are in larger size families than if they are in smaller size families.

\section{Methodology}

The present research is exploratory, aiming to examine the influences of the national cultural constructs of individualism-collectivism and power distance, and consumer socialization effects on adolescent's influence on family vacation decisions, according to the mother's perception.

The universe in this study is formed of Portuguese families, with at least one adolescent (between 12 and 19 years). There is no knowledge of studies about the impact of cultural constructs and socialization consumer on adolescent's influence on family vacations purchase in Europe, so this study offers a contribution in the family consumer behavior area.

The generality of studies used data collection from convenience samples (Aleti et al. 2015, Srivastava 2015, Kim and Lee 1997). In the present study, there was the same difficulty, due to the lack of information provided by official organisms, it was necessary to use a non-probabilistic sample. The collected sample was focused on households with at least one adolescent child between the ages of 12 and 19, which is consistent with previous research (Aleti et al. 2015, Srivastava 2015, Kim and Lee 1997, Beatty and Talpade 1994).

In the literature on this area, several authors pointed out the importance of study product or service categories for family use (Belch et al. 2005, Kim and Lee 1997, Beatty and Talpade 1994). In the present investigation the selection of the service category to be studied derives from the literature review, with the decision on the family vacations (Kim and Lee 1997, Foxman et al. 1989a, b, Foxman and Tansuhaj 1988). More, little is known about the adolescent's influence in this category of service on the final purchase decision.

The questionnaire survey was the method of data collection chosen for this study, which is consistent with past practices (Aleti et al. 2015, Srivastava 2015, Shoham and Dalakas 2005, 2003, Beatty and Talpade 1994).

The questionnaire structure aimed to pursue the research objectives outlined. A pre-test was carried out that led to small changes in the questionnaire final structure. The suggestions presented by the 18 respondents in that phase concerned some difficulty in understanding certain expressions used in the initial version. The measurement scales for variables studied were adapted from past research on this field (see Table 1). 
Table 1. Linking the Model to the Questionnaire

\begin{tabular}{|c|c|}
\hline Variables in study & Adapted from... \\
\hline Explained variable & \multirow[b]{2}{*}{$\begin{array}{l}\text { Shoham e Dalakas (2003); Beatty e } \\
\text { Talpade (1994) }\end{array}$} \\
\hline $\begin{array}{l}\text { - Adolescent Influence on Family } \\
\text { Purchase Decisions }\end{array}$ & \\
\hline \multicolumn{2}{|l|}{ Explanatory variables } \\
\hline $\begin{array}{ll}\text { - } & \text { Individualism vs collectivism } \\
\text { - } & \text { Power distance } \\
\text { - } & \text { Parental communication style } \\
\text { - } & \text { Internet influence } \\
\text { - } & \text { Television influence } \\
\text { - } & \text { Service knowledge } \\
\text { - } & \text { Family size } \\
\text { - } & \text { Family type } \\
\end{array}$ & $\begin{array}{l}\text { Wu (2006), Hofstede (2001) } \\
\text { Wu (2006), Hofstede (2001) } \\
\text { Chan and McNeal (2003) } \\
\text { Kaur and Medury (2011) } \\
\text { Kaur and Medury (2011) } \\
\text { Beatty e Talpade (1994) } \\
\text { Ahuja and Stinson (1993) } \\
\text { Ahuja and Stinson (1993) }\end{array}$ \\
\hline
\end{tabular}

\section{Explained Variable}

Several authors have used a likert scale to measure the adolescent's final decision relative influence on decision making process considering parents and adolescents participation (Shahrokh and Khosravi 2014, Mangleburg et al. 1999, Kim and Lee 1997, Beatty and Talpade 1994).

The explained variable measurement scale used was based on past research (Shoham and Dalakas 2003, Beatty and Talpade 1994). The mother's perception may in a range from 1 to 7 points (where $1=\mathrm{I}$ had no influence, and $7=\mathrm{I}$ had all influence).

\section{Explanatory Variables}

The "individualism vs collectivism" is measured using the Hofstede (2001) scale. For this variable, twelve items where used, each one in a seven-point Likert scale. For parental communication style the Chan and McNeal (2003) seven-point Likert scale was used, ranked completely disagree (1) to completely agree (7). The "internet influence" variable used Kaur and Medury (2011) nine items with sevenpoint Likert scale, ranked completely disagree (1) to completely agree (7). The "television influence" variable also used Kaur and Medury (2011) nine items adapted to television, with the same seven-point Likert scale, ranked completely disagree (1) to completely agree (7).

The variable "service knowledge" represents the subjective knowledge, and will be measured according to Beatty and Talpade (1994) scale. A sevenpoint Likert scale is used, ranked completely disagree (1) to completely agree (7). The item to be measured will be translated by the phrase: "before buying this service I would describe myself as being very familiar with this service category." The variable "family size" uses the ordinal scale of Ahuja and Stinson (1993), ranging from 2 persons to 6 or more persons. Finally, the family type used the Ahuja and Stinson (1993) dual scale. 


\section{Data Collection Procedures and Sample}

The research was conducted in May 2018. In order to carry out the data collection, 15 high-schools were contacted, in Lisbon district. With regard to the sampling process, the Lisbon district presents an important demographic profile in Portugal, namely the average size of the household. Thus, letters were sent to the Executive Councils of several schools in Lisbon area, and all the schools contacted agreed to participate in the study. Then, for each school level the form teachers were contacted, and instructed the teachers in each class to provide a questionnaire and a letter to the mother of each student, requesting her participation. During this phase, 1,800 questionnaires were delivered by the teachers in the classrooms during May 2018. Students, aged 12 to 19 years, were instructed to deliver the questionnaires to their mothers and to return them, fully completed, some days later. Finally, the questionnaires were collected from the high-schools during May 2018. This resulted in a total of 726 questionnaires fully answered by mothers, which meant a response rate of $40.3 \%$. That represents a higher rate than most of main previous studies (Kaur and Medury 2013, Shergill et al. 2013, Wu 2006).

\section{Statistical Techniques Used}

The research objectives determine the method to be used in data analysis. Several authors have used linear regression to study the adolescent's influence in family purchase decisions (Mangleburg et al. 1999, Beatty and Talpade 1994). Nonetheless, is scarce the use of logistic regression in the study of adolescent's influence on family purchasing decisions (Baía 2018). There are two main reasons for choosing logistic regression: the variables level of measurement and a binary explained variable.

\section{Variables Measurement}

The explanatory variables considered do not raise any issues regarding the use of logistic regression (Hutcheson and Sofroniou 1999). The explanatory variables considered in the present investigation involve three types of scales: categorical, ordinal and interval. Individualism-collectivism, parental communication style, internet influence, television influence, service knowledge are interval variables, with one or more items classified in Likert scales with seven points. The family size is an ordinal variable, ranging from 2 to 6 or more persons, and family type is a binary variable classified in single-parent family or traditional family.

\section{The Explained Variable}

The explained variable, measured through a seven-point range scale, was transformed into a dichotomous variable. Therefore, the values that are in the range of 5 to 7 , will correspond to $0=$ does not influence; and values from 1 to 4 will correspond to the value $1=$ influence (Baía 2018). 


\section{Variables Selecting Method for the Logistic Regression Model}

The Forward LR method of inclusion of variables will be used in logistic regression model in study. For Hutcheson and Sofroniou (1999), the ordinal or interval data can be transformed into dichotomous data, allowing its analysis the use of logistic regression models.

\section{Data Analysis and Findings}

\section{Internal Consistency}

Cronbach's $\alpha$ ranks high in most researcher preferences among the several available methods to estimate internal consistency. The reliability of a measure refers to its ability to be consistent (Maroco and Garcia-Marques 2006). Mostly Cronbach's $\alpha$ coefficients presented values above 0.8 , indicating good reliability. The individualism-collectivism scale presents a value of 0.743 , and being above 0.7, is taken as acceptable reliability (Gliem and Gliem 2003). The power distance scale presented a value of 0.874 , almost excellent accordingly to Gliem and Gliem (2003).

The parental communication style scale has a 0.812 value, that represents a good Cronbach's $\alpha$ coefficient. For the internet influence, a 0.823 coefficient, also good. As for the television influence scale, 0.828 was found, which is a good Cronbach's $\alpha$ coefficient (idem 2003).

\section{Profile of Respondents}

The age group from 16 to 19 years old represents $61.5 \%$ of the total sample collected (see Table 2). Results also point to a distribution of $53.4 \%$ for female adolescents of the total number of adolescents under study.

Regarding mother's age, the most frequent age group is 35 to 49 years, with $70.1 \%$. The second most frequent age group is 50 to 64 years, with a rate of $22.4 \%$ of the total of respondents.

The most frequent category of mother's educational level corresponds to high school education, with a rate of $36 \%$ of the total of respondents. The second most frequent category corresponds to basic school, with $28 \%$ of the total. Only $23.3 \%$ had a university graduation level (see Table 2).

The farmers and skilled workers represent the most frequent category concerning mother's professional category, with a rate of $18.2 \%$ of respondents. The second most frequent category corresponds to workers, builders and similar workers, with $17.6 \%$ of the total.

The most frequent household monthly post-tax income interval is the 1,001 to 1,500 euros range, with $30.7 \%$. The second most frequent monthly income range is 500 and 1,000 euros, with $24.5 \%$ (see Table 2). 
Table 2. Profile of Respondents (percentage)

\begin{tabular}{|c|c|c|c|}
\hline \multirow{2}{*}{\multicolumn{2}{|c|}{\begin{tabular}{|l|} 
Demographics \\
Adolescent's age range
\end{tabular}}} & \multicolumn{2}{|c|}{ Valid percent Cumulative percentage } \\
\hline & & & \\
\hline 12 to 15 & & 38.5 & 38.5 \\
\hline 16 to 19 & & 61.5 & 100 \\
\hline \multicolumn{4}{|l|}{ Adolescent's gender } \\
\hline Male & & 46.6 & 46.6 \\
\hline Female & & 53.4 & 100 \\
\hline \multicolumn{4}{|l|}{ Mother's age range } \\
\hline 25 to 34 & & 6.6 & 6.6 \\
\hline 35 to 49 & & 70.1 & 76.7 \\
\hline 50 to 64 & & 22.4 & 99.2 \\
\hline More than 64 & & 0.8 & 100 \\
\hline \multicolumn{4}{|c|}{ Mother's educational level } \\
\hline No Schooling & & 1 & 1 \\
\hline Basic education & & 28 & 29 \\
\hline High school & & 36 & 65.6 \\
\hline Bachelor's Degree & & 5.8 & 71.4 \\
\hline Universitary graduation & & 23.3 & 94.8 \\
\hline Masters or $\mathrm{PhD}$ & & 5.2 & 100 \\
\hline \multicolumn{4}{|c|}{ Mother's professional category } \\
\hline Housewife & & 11.5 & 11.5 \\
\hline \multicolumn{2}{|c|}{ Low-qualified or Unskilled Workers } & 8.8 & 20.3 \\
\hline \multicolumn{2}{|c|}{ Plant and Machine Operators and Assembly Workers } & 12.7 & 33.1 \\
\hline \multicolumn{2}{|c|}{ Workers, Builders and Similar Workers } & 17.6 & 50.7 \\
\hline \multicolumn{2}{|c|}{ Farmers and Skilled Workers in Agriculture and Fisheries } & 18.2 & 68.9 \\
\hline \multicolumn{2}{|c|}{ Service and Sales Personnel } & 1.7 & 70.6 \\
\hline \multicolumn{2}{|c|}{ Administrative and Similar Personnel } & 6.4 & 77 \\
\hline \multicolumn{2}{|c|}{ Technicians and Professionals of Intermediate Level } & 3.4 & 80.4 \\
\hline \multicolumn{2}{|c|}{ Specialists of the Intellectual and Scientific Professions } & 7.3 & 87.7 \\
\hline \multicolumn{2}{|c|}{ Senior Management and Directors } & 12.3 & 100 \\
\hline \multicolumn{2}{|l|}{ Family income } & & \\
\hline Less than 500 euros & & 4.5 & 4.5 \\
\hline \multicolumn{2}{|l|}{ From 500 to 1,000 euros } & 24.5 & 29 \\
\hline \multicolumn{2}{|c|}{ From 1,001 to 1,500 euros } & 30.7 & 59.7 \\
\hline \multicolumn{2}{|c|}{ From 1,501 to 2,000 euros } & 15.2 & 74.9 \\
\hline \multicolumn{2}{|c|}{ From 2,001 to 2,500 euros } & 13.2 & 88.2 \\
\hline \multicolumn{2}{|c|}{ From 2,501 to 3,000 euros } & 5.9 & 94.1 \\
\hline \multirow{2}{*}{\multicolumn{2}{|c|}{$\begin{array}{l}\text { From 3,001 to 5,000 euros } \\
\text { More than 5,000 euros }\end{array}$}} & 4.5 & 98.6 \\
\hline & & 1.4 & 100 \\
\hline
\end{tabular}


Table 3. Family Demographic Characteristics (percentage)

\begin{tabular}{|l|r|r|}
\hline Demographics & Valid percent Cumulative percentage \\
\hline Family Size & & \\
\hline 2 persons & 18.7 & 4.7 \\
\hline 4 persons & 35.5 & 23.8 \\
\hline 5 persons & 27.5 & 59.6 \\
\hline 6 or more persons & 12.5 & 87.4 \\
\hline Family type & & 100 \\
\hline Single-parent & 29.9 & 29.9 \\
\hline Traditional & 70.1 & 100 \\
\hline
\end{tabular}

The most frequent category of family size, with a rate of $35.5 \%$ of the total of respondents, is four persons. The second most frequent category corresponds to five persons' household, with $27.5 \%$ of the total (see Table 3). The traditional family represent the most frequent category concerning family type, with a rate of $70.1 \%$ of respondents, which also means that for each ten adolescents, three of them lives in a single-parent household.

\section{Explanatory Variables}

Next, the adolescent's influence on family vacations purchase explanatory variables will be analyzed.

\section{$\underline{\text { Individualism-Collectivism }}$}

Individualism-collectivism adds explanatory capacity to the adolescent influence model on family vacations purchase decision. Thus, $\mathrm{H} 1$ is verified, so adolescents are perceived as having more influence on family purchases when they are in individualist culture than when they are in collectivist culture (see Table 4).

Table 4. Logistic Regression for Family Vacations (variables in equation)

\begin{tabular}{|c|c|c|c|c|c|c|c|c|c|}
\hline & variables & $\mathrm{B}$ & S.E. & Wald & $\mathrm{df}$ & Sig. & $\operatorname{Exp}(B)$ & \multicolumn{2}{|c|}{$95 \%$ C.I.for EXP(B) } \\
\hline & & & & & & & & Lower & Upper \\
\hline 7th step & Service knowledge & 0.351 & 0.053 & 43.202 & 1 & 0 & 1.42 & 1.279 & 1.577 \\
\hline & Individualism-collectivism & 0.169 & 0.077 & 4.761 & 1 & 0.029 & 1.184 & 1.017 & 1.378 \\
\hline & Parental communication style & -0.186 & 0.084 & 4.895 & 1 & 0.027 & 0.83 & 0.704 & 0.97 \\
\hline & Internet influence & -0.306 & 0.099 & 9.519 & 1 & 0.002 & 0.736 & 0.606 & 0.894 \\
\hline & Television influence & 0.991 & 0.214 & 2.407 & 1 & 0 & 2.693 & 1.77 & 4.0 \\
\hline & Family type & 1.136 & 0.197 & 33.171 & 1 & 0 & 3.116 & 2.116 & 4.586 \\
\hline & Family size & -0.539 & 0.197 & 7.45 & 1 & 0.006 & 0.583 & 0.396 & 0.85 \\
\hline & Constant & -2.838 & 0.682 & 1.299 & 4 & 0 & 0059 & & \\
\hline
\end{tabular}




\section{Power Distance}

Table 5 reveals that power distance doesn't add explanatory capacity to the adolescent influence model in the decision to buy family vacations. Thus, $\mathrm{H} 2$ is not verified, so that adolescents in low power distance culture are not perceived as having more influence on family purchases than those in high power distance one.

Table 5. Logistic Regression for Family Vacations (variables not in equation)

\begin{tabular}{|l|l|c|r|r|r|}
\hline & variables & Score & df & \multicolumn{1}{|l|}{ Sig. } \\
\hline 7th Step & Power distance & 0.001 & 1 & 0.97 \\
\hline & Overall Statistics & 0.001 & 1 & 0.97 \\
\hline
\end{tabular}

\section{$\underline{\text { Parental Communication Style }}$}

Parental communication style does add explanatory capacity to the adolescent influence model in the decision to buy family vacations. Thus, H3 is verified, so adolescents with laissez-faire and pluralistic parents are perceived as having more influence on family purchases than those with protective and consensual parents (see Table 4).

\section{Internet Influence}

The internet influence adds explanatory capacity to the adolescent influence on family vacations. Therefore, $\mathrm{H} 4$ is verified, so internet influence is positively related to the adolescent's influence on family purchase decisions, with adolescents who receive more internet influence have greater influence on family purchases (see Table 4).

\section{$\underline{\text { Television Influence }}$}

The television influence adds explanatory capacity to the adolescent influence on family vacations. Thus, $\mathrm{H} 5$ is verified, thus television influence is positively related to the adolescent's influence on family purchase decisions, so adolescents who receive more television influence have greater influence on family purchases (see Table 4).

\section{$\underline{\text { Service Knowledge }}$}

Table 4 shows that service knowledge adds explanatory capacity to the adolescent influence model in the decision to buy family vacations. Thus, H6 is verified, so adolescents with greater service knowledge exert more influence on family vacations purchase than those adolescents with less service knowledge. 
Family Type

The family type adds explanatory capacity to the adolescent influence on family vacations. Thereby, $\mathrm{H} 7$ is verified, so adolescents are perceived as having more influence on family purchases if they live in single-parent families than if they live in traditional families (see Table 4).

\section{$\underline{\text { Family Size }}$}

As can be seen on Table 4, family size adds explanatory capacity to the adolescent influence on family vacations. $\mathrm{H} 8$ is verified, and so we can conclude adolescents are perceived as having more influence on family purchases if they are in larger size families than if they are in smaller size families.

\section{Explanatory Variables Interpretation}

For the study of the adolescent's influence on decision to buy family vacations, the -2LL analysis allows us to conclude that the exogenous variables add explaining capacity to adolescent's influence on that service purchase. This is reinforced by the Chi-square value, when pointing out that there is a large part of the model explained variance when considering individualism, parental communication style, internet influence, television influence, adolescent's service knowledge, family size and family type as purchase relevant explanatory variables.

\section{Discussion}

A total of 726 fully completed questionnaires from the surveyed was reached, which is a larger sample than most past researchers presented (Al-Zu'bi 2016, Ashraf and Khan 2016, Ali et al. 2013, Chikweche et al. 2012, Chitakunye 2012, Mangleburg et al. 1999, Darley and Lim 1986).

In line with most past studies on household purchases, the present investigation used a convenience sample (Al-Zu'bi 2016, Ashraf and Khan 2016, Ali et al. 2013, Chikweche et al. 2012, Chitakunye 2012).

\section{Internal Validity}

The divergence of opinions among family members when questioned about adolescent's influence raised, in past research, internal validation issues (Beatty and Talpade 1994, Foxman et al. 1989b, Belch et al. 1985).

Several researchers have collected data questioning one or both parents and the adolescent in studies on adolescent influence on purchasing decisions (Watne and Winchester 2011, Ishaque and Tufail 2014, Shoham and Dalakas 2005, Beatty and Talpade 1994, Foxman et al. 1989a, b, Belch et al. 1985), which has raised the issue of perception differences between the members questioned, and subsequent lack of model internal validity. The mother has been pointed out in several studies 
as the most reliable member of the family in that measurement (Neely 2005, Mangleburg et al. 1999, Kim and Lee 1997). Thus, in this study, the mother's inquiry was chosen, preserving internal validation of the influence construct.

When comparing mother's influence with adolescent's influence, or what one can call relative influence, the scale used shall also provide external validation (Baía 2018).

\section{Internal Consistency}

These values are consistent with previous research (Ahuja and Stinson 1993). Mostly, past researchers did not refer to the internal consistency of scales used in their studies (Al-Zu'bi 2016, Ashraf and Khan 2016, Ishaque and Tufail 2014, Ali et al. 2013, Chikweche et al. 2012, Watne and Winchester 2011, Beatty and Talpade 1994, Foxman et al. 1989a, b).

\section{Conclusions}

In light of the results found in the present research, one can conclude that: There is a significant adolescent's influence on family vacations purchase. Individualism, parental communication style, internet influence, television influence, adolescent's service knowledge, family size and structure are explanatory variables of the adolescent's influence for that purchase. The adolescent has more influence on purchase vacations for family consumption in individualistic cultures. He/she has more influence on that purchase when the dominant parental communication styles are laissez-faire and pluralistic. Also, the adolescent participation on those purchases are higher when he/she's exposed in higher degree to internet influence and to television influence. Their influence's higher when they possess higher service knowledge. Finally, the adolescents' influence as a major impact on that purchase when they live in bigger size households, and within single-parent families.

\section{Limitations and Recommendations}

Although the present research adds some important contributions to the theoretical-conceptual framework in this field, providing a response to national cultural constructs and consumer socialization effects on adolescent's influence on family vacation decisions, the results don't entirely explain the phenomenon. Thereby, other variables must also be considered in order to provide a more complete explanation on the adolescent's influence for this service decisions. Furthermore, in this study, the use of a convenience sample does not allow us to extrapolate the results, although this procedure is consistent with past research (Aleti et al 2015, Yang et al. 2014, Chaudhary and Gupta 2012, Feng et al. 2011).

More, collecting data solely from mothers, although being considered the most reliable information source within families (Isin and Alkibay 2011, Beatty and Talpade 1994), was insufficient by some authors which have chosen to 
inquire both adolescent and one parent (Al-Zu'bi 2016, Ashraf and Khan 2016, Mau et al. 2014, 2016, Goswami and Khan 2015, Sondhi and Basu 2014).

Finally, it is suggested that future research studies the effect of friends as agents of socialization in the influence of adolescents. This aspect has been little attention and needs deeper research. Many have seen the internet as a way of socializing through the conviviality of teens with their peers. However, this relationship does not run out on the internet.

\section{Research Contributions}

The present research provides several contributions to this area of knowledge. In the first place, the main contribution of the present research is the suggestion of a theoretical-conceptual framework that provides explanatory capacity of national cultural constructs and consumer socialization effects on adolescent's influence on family vacation decisions, according to the mother's perception. It also reinforces the importance of including the adolescent in the final decision for family vacations, which is an innovation in this area of research.

More, the research indicated the adolescent's influence in the purchase of family vacations, which is also an innovative result in traditional families. The results of the logistic regression analysis point to individualism, parental communication style, internet influence, television influence, adolescent's service knowledge, family size and structure as purchase important explanatory variables on the considered purchase. These results are innovative in the study of family purchases.

Finally, the results point to the relevance of considering adolescent as an influencer on family vacations final decision, indicating that he/she has an important role when considering relevant services for family consumption. This can be considered a very relevant contribution, indicating that the adolescent does not only participate in the purchase of services for own use, as much of previous research indicated.

\section{Business Implications}

The study offers a contribution to the companies by providing evidence of the adolescent's influence on the purchases of family vacations. Given the adolescents relevance within family decisions, it is important that marketers focus their efforts on adolescent satisfaction, adopting strategies adjusted to the families. Should those professionals direct the marketing messages to adolescents living in individualistic cultures. Marketers approach to family markets should also be more precise if they target adolescents in families when parental communication styles are laissez-faire and pluralistic. Their messages will also become more efficient targeting adolescents with higher internet influence, with higher television influence. It's important for companies to target also adolescents with higher service knowledge, living in bigger size families and in single-parent structures. These results are innovative in the study of family purchases when it comes to buying family vacations. 
If a decision is considered to be largely influenced by adolescents, then the messages should be addressed to this family member. In the present investigation it was concluded that adolescents represent an active influential market in the family vacations, and so marketers should adopt strategies that reflect the adolescent's relative importance in those decisions, as well as the demographic characteristics of these households. On the other hand, marketers should focus their efforts not only on adolescent satisfaction in products/services for their personal use, but also on those categories for family use.

\section{Suggestions for Future Research}

In addition to the products/services that may be more associated with certain patterns of consumption characteristic of families, it is important to point out as research opportunity the study on the adolescent's influence in the purchasing decisions in those households for several other products/services. Application of the model to other services for family consumption, like eating out, hotel services, and other leisure activities. It's important to explore the behavior nature of adolescents living on single-parent contexts, and to consider specific product and service categories that those family structures demand for.

On the other hand, the services/products of perceived adolescent's influence are not properly exhausted. Research in this area should focus on the influence of adolescents in the choice of services/products that are shared by the family versus those used by the parents; explore the mechanisms of decision making between male and female across this age range; explore differences between income ranges; and to go deeper in the study of the impact of mothers' occupational status on adolescents' influence.

\section{References}

Ahuja RD, Stinson KM (1993) Female-headed single parent families: an exploratory study of children's influence in family decision making. Advances in Consumer Research 20: 469-474.

Ahuja RD, Walker M (1994) Female-headed single parent families: comparisons with dual parent households on restaurant and convenience food usage. Journal of Consumer Marketing 11(4): 41-54.

Ahuja RD, Capella LM, Taylor RD (1998) Child influences, attitudinal and behavioral comparisons between single parent and dual parent households in grocery shopping decisions. Journal of Marketing Theory and Practice 6(1): 48-62.

Akinyele ST (2010) The influence of children on family purchasing decisions in Ota, Nigeria. Journal of Contemporary Management Research 4(2): 1-11.

Al-Zu'bi A (2016) The direct and indirect influences of locus of control on Jordanian parents' communication patterns: Consumer socialization and cultural perspectives. Journal of Islamic Marketing 7(2): 167-186.

Aleti T, Brennan L, Parker L (2015) Family communication for the modern era: a typology. Young Consumers 16(4): 367-384.

Ali A, Ravichandran N, Batra DK (2013) Children's choice of influence strategies in family purchase decisions and the impact of demographics. Vision 17(1): 27-40. 
Ashraf M, Khan KM (2016) Adolescents' role in family decision-making for services in India. Young Consumers 17(4): 388-403.

Baía J (2018) Mothers' Perceptions of adolescents' influence on the purchase decisions of family vacations. Athens Journal of Tourism 5(2): 111-132.

Barber N (2013) Investigating the potential influence of the internet as a new socialization agent in context with other traditional socialization agents. Journal of Marketing Theory and Practice 21(2): 179-193.

Beatty SE, Talpade S (1994) Adolescent influence in family decision making: a replication with extension. Journal of Consumer Research 21(9): 332-341.

Belch, GE, Belch MA, Ceresino G (1985) Parental and teenage child influences in family decision making. Journal of Business Research 13(2): 163-176.

Belch MA, Krentlera KA, Willis-Flurry LA (2005) Teen internet mavens: influence in family decision making. Journal of Business Research 58(5): 569-575.

Carlson L, Grossbart S (1990) An investigation of mothers' communication orientations and patterns. Advances in Consumer Research 17: 804-812.

Caruana A, Vassallo R (2003) Children's perception of their influence over purchases: the role of parental communication patterns. Journal of Consumer Marketing 20(1): 5566.

Carr N (2006) A comparison of adolescents' and parents' holiday motivations and desires. Tourism and Hospitality Research 6(2): 129-142.

Chan K, McNeal J (2002a) Parent-child communications about consumption and advertising in China. Journal of Consumer Marketing 20(4): 317-334.

Chan K, McNeal J (2003) Parental concern about television viewing and children's advertising in China. International Journal of Public Opinion Research 15(2): 151166.

Chaudhary M, Gupta A (2012) Children's influence in family buying process in India. Young Consumers 13(2): 161-175.

Chikweche T, Stanton J, Fletcher R (2012) Family purchase decision making at the bottom of the pyramid. Journal of Consumer Marketing 29(3): 202-213.

Chitakunye P (2012) Recovering children's voices in consumer research. Qualitative Market Research: An International Journal 15(2): 206-224.

Churchill GA, Moschis GP (1979) Television and interpersonal influences on adolescent consumer learning. Journal of Consumer Research 6(1): 23-35.

Commuri, S. and Gentry, J. 2000, Opportunities for family research in marketing. Academy of Marketing Science Review, ABI/INFORM Global 8: 1-34. Available at https://bit.ly/2KgdhDp.

Darley WK, Lim JS (1986) Family decision making in leisure-time activities: an exploratory investigation of the impact of locus of control, child age influence factor and parental type on perceived child influence, Advances in Consumer Research 13, RJ Lutz (eds), Provo, UT: Association for Consumer Research, 370-374. Available at: http://acrwebsite.org/volumes/6521/volumes/v13/NA-13.

Dotson MJ, Hyatt EM (2005) Major influence factors in children's consumer socialization. Journal of Consumer Marketing 22(1): 35-42.

Ekstrom KM, Tansuhaj PS, Foxman ER (1987) Children's influence in family decisions and consumer socialization: a reciprocal view. Advances in Consumer Research 14: 283-287.

Feng C, Collins R, Song W (2011) The influences of national cultural constructs on marketing studies. African Journal of Business Management 5(26): 10893-10899.

Foxman ER, Tansuhaj PS (1988) Adolescents' and mothers perceptions of relative influence in family purchase decisions: patterns of agreement and disagreement. Advances in Consumer Research 15: 449-453. 
Foxman ER, Tansuhaj PS, Ekstrom KM (1989a) Family members' perceptions of adolescents' influence in family decision making. Journal of Consumer Research 15(3): 482-491.

Foxman ER, Tansuhaj PS, Ekstrom KM (1989b) Adolescents' influence in family purchase decisions: a socialization perspective. Journal of Business Research 18(3): $159-172$.

Gliem JA, Gliem RR (2003) Calculating, Interpreting, and Reporting Cronbach's Alpha Reliability Coefficient for Likert-Type Scales, Midwest Research to Practice Conference in Adult, Continuing, and Community Education, The Ohio State University, Columbus, OH, October 8-10, 2003.

Goswami S, Khan S (2015) Impact of consumer decision-making styles on online apparel consumption in India. Vision 19(4): 303-311,

Haq MR, Rahman SD (2015) Role of reality TV as a consumer-socialization agent of teenagers in a developing country. International Journal of Emerging Markets 10(3): 598-618.

Hofstede GH (1993) Cultural constraints in management theories. The Executive 7,1 (Feb 1993), ABI/INFORM Collection, 81-94.

Hofstede GH (1994) Management scientists are humans. Management Science 40(1): 413.

Hofstede GH (2001) Culture's Consequences: Comparing Values, Behaviors, Institutions and Organizations across Nations. Beverly Hills, CA: Sage.

Hutcheson G, Sofroniou N (1999) The Multivariate Social Scientist. Los Angeles: Sage Publications.

Isin F, Alkibay S (2011) Influence of children on purchasing decisions of well-to-do families. Young Consumers 12(1): 39-52.

Ishaque A, Tufail M (2014) Influence of children on family purchase decision: empirical evidence from Pakistan. International Review of Management and Business Research 3(1): 162-173.

Kaur P, Medury Y (2011) Impact of the internet on teenagers' influence on family purchases. Young Consumers 12(1): 27-38.

Kaur P, Medury Y (2013) SEM approach to teen influence in family decision making. Contemporary Management Research 9(3): 323-342.

Kaur P, Singh R (2006) Children in family purchase decision making in India and the west: a review. Academy Marketing Science Review 2006(8): 1-30.

Khoo-Lattimore C, Prayag G, Cheah BL (2016) Kids on board: exploring the choice process and vacation needs of asian parents with young children in resort hotels. Journal of Hospitality Marketing and Management 24(5): 1-31.

Kim C, Lee H (1997) Development of family triadic measures for children's purchase influence. Journal of Marketing Research 34(3): 307-321.

Kim C, Yang Z, Lee H (2015) Parental style, parental practices, and socialization outcomes: An investigation of their linkages in the consumer socialization context, Journal of Economic Psychology 49:15-33.

Kushwaha T (2017) Parental style and television socialization of children and adolescents: a perceptual study in the indian context. South Asian Journal of Management 24( 3): 88-105.

Lackman C, Lanasa J (1993) Family decision-making theory: an overview and assessment. Psychology \& Marketing 10(2): 81-93.

Lee, C. K., Conroy, D. M. and Hii, C. 2003, The Internet: A Consumer Socialization Agent for Teenagers. ANZMAC 2003 Conference Proceedings, Adelaide 1-3(12): 1708-1715. 
Lee CKC, Beatty SE (2002) Family structure and influence in family decision making. Journal of Consumer Marketing 19(1): 24-41.

Leng CY, Botelho D (2010) How does national culture impact on consumers' decisionmaking styles? a cross cultural study in Brazil, the United States and Japan. Brazilian Administration Review 7(3): 260-75.

Luczak C, Younkin N (2012) Net generation: a conceptual framework of the consumer socialization process. Academy of Marketing Studies Journal 16(2): 47-51.

Mangleburg TF (1990) Children's influence in purchase decisions: a review and critique, Advances in Consumer Research 17, ME Goldberg, G Gorn, RW Pollay (eds), Provo, UT: Association for Consumer Research, 813-825. Available at: http://acrwebsite.org/volumes/7108/volumes/v17/NA-17.

Mangleburg TF, Bristol T (1998) Socialization and Adolescents' Skepticism toward Advertising. Journal of Advertising 27(3): 11-21.

Mangleburg TF, Grewal D, Bristol T (1999) Family Type, Family Authority Relations, and Adolescents' Purchase Influence, Advances in Consumer Research 26(1999), 379-384.

Maroco J, Garcia-Marques T (2006) Qual a fiabilidade do alfa de Cronbach? Questões antigas e soluções modernas?, Laboratório de Psicologia, 4, 1: 65-90, Instituto Superior de Psicologia Aplicada, Portugal. Available at: http://publicacoes.ispa.pt/in dex.php/lp/article/viewFile/763/706.

Mau G, Schramm-Klein H, Reisch L (2014) Consumer socialization, buying decisions, and consumer behaviour in children: introduction to the special issue. Journal of Consumer Policy 37(2): 155-160.

Mau G, Schuhen M, Steinmann S, Schramm-Klein H (2016) How children make purchase decisions: behaviour of the cued processors. Young Consumers Bradford 17(2): 111126.

Mooij M (2015) Cross-cultural research in international marketing: clearing up some of the confusion. International Marketing Review 32(6): 646-662.

Mooij M, Hofstede G (2010) The Hofstede model. International Journal of Advertising 29(1): 85-110.

Moschis G, Churchill G (1979) An analysis of the adolescent consumer. Journal of Marketing 43(3): 40-48.

Moschis G, Mitchell L (1986) Television advertising and interpersonal influences on teenagers' participation in family consumer decisions. Advances in Consumer Research 13: 181-186.

Moschis G, Moore R (1979) Decision making among the young: a socialization perspective. Journal of Consumer Research 6(2): 101-112.

Niu HJ (2013) Cyber peers' influence for adolescent consumer in decision-making styles and online purchasing behavior. Journal of Applied Social Psychology 43(6): 12281237.

Neely S (2005) Influences on consumer socialization, Young Consumers. World Advertising Research Center, Quarter 1: 63-69.

Neulinger A, Zsoter B (2014) Mother-child interactions in youth purchase decisions. Society and Economy 36(3): 387-406.

Niemczyk A (2015) Family decisions on the tourism market. Economics \& Sociology 8(3): 272-283.

Rose GM, Bush VD, Kahle L (1998) The influence of family communication patterns on parental reactions toward advertising: A cross-cultural national examination. Journal of Advertising 27(4): 71-85.

Shah R, Mittal B (1997) Toward a theory of intergenerational influence in consumer behaviour: an exploratory essay. Advances in Consumer Research 24: 55-60. 
Shahrokh ZD, Khosravi ME (2014) Children's influence in family consumption decisions: an integrative approach. International Review of Management and Business Research 3(2): 1275-1287.

Sharma A, Sonwaney V (2013) Influence of Children on Family Purchase Decisions in Urban India: An Exploratory Study. International Journal of Marketing \& Business Communication 2(2): 32-43.

Shergill S, Sekhon H, Zhao M (2013) Parents' perception of teen's influence on family purchase decisions: A study of cultural assimilation. Asia Pacific Journal of Marketing and Logistics 25(1): 162-177.

Shoham A, Dalakas V (2005) He said, she said ... they said: parent's and children's assessment of children's influence on family consumption decisions. Journal of Consumer Marketing 3(22): 152-160.

Shoham A, Dalakas V (2003) Family consumer decision making in Israel: the role of teens and parents. Journal of Consumer Marketing 3(20): 238-251.

Singh R, Nayak JK (2014) Peer Interaction and Its Influence on Family Purchase Decision: A Study among Indian Teenagers. Vision 18(2) 81-90.

Sondhi N, Basu R (201) Role of children in family purchase across Indian parental clusters. Young Consumers 15(4): 365-379.

Srivastava A (2015) Consumer Decision-Making Styles of Indian Adolescents. Contemporary Management Research; Sansia 11(4): 385-408.

Yang Z, Kim C, Laroche M, Lee H (2014) Parental style and consumer socialization among adolescents: A cross-cultural investigation. Journal of Business Research 67(3): 228-236.

Yang Z, Laroche M (2011) Parental responsiveness and adolescent susceptibility to peer influence: a cross-cultural investigation. Journal of Business Research 64(9): 979987.

Ward S (1974) Consumer socialization. Journal of Consumer Research 1(2): 1-14.

Watabe A, Hibbard DR (2014) The influence of authoritarian and authoritative parenting on children's academic achievement motivation: a comparison between the united states and Japan. North American Journal of Psychology 16(2): 359-382.

Watne TA, Lobo A, Brennan L (2011) Children as secondary socialisation agents for their parents. Young Consumers 12(4): 285-294.

Watne TA, Brennan L, Parker L (2015) Consumer socialisation agency within threegenerational Vietnamese families. Young Consumers 16(2): 172-188.

Watne TA, Brennan L, Winchester T (2014) Consumer Socialization Agency: Implications for family decision-making about holidays. Journal of Travel \& Tourism Marketing 31(6): 681-696.

Watne TA, Winchester T (2011) Family Holiday Decision Making: The Knowledge And Influence of Adolescent Children and Parents. In ANZMAC 2011 conference proceedings: Marketing in the Age of Consumerism: Jekyll or Hyde?, ANZMAC, Perth W. A., 1-9.

Wu MY (2006) Hofstede's cultural dimensions 30 years later: a study of taiwan and the united states. Intercultural Communication Studies XV: 33-42. 
